\title{
Effects of Simmer Current on Flashlamp Impedance and Their Combined Influence on the Output of a Quasi-CW Nd:YAG Laser
}

\author{
R. Arya, Joy M. Thomas, A. G. Bhujle, and D. D. Bhawalkar
}

\begin{abstract}
This paper reports the results of investigations carried out on the influence of simmer current on flashlamp impedance and performance of a flashlamp-pumped Nd:YAG laser operating in the quasi-CW mode. A pulse power source with an adjustable output pulsewidth (1-20 ms) and an adjustable simmer current source $(30 \mathrm{~mA}$ to 6 A) developed specifically for the study were used. It is found that the simmering of the lamp reduces the impedance factor of the lamp, increases the correct arc diameter, and reduces the peak current density of the flashlamp discharge. It improves the efficiency of the flashlamp pump source and, hence, the efficiency of the Nd:YAG laser also. An appropriate choice of the simmer current, using the results obtained, can lead to higher efficiency of the laser and increased life of the lamp.
\end{abstract}

Index Terms-Flashlamp impedance, Nd:YAG laser, quasi-CW laser, simmer current, solid-state lasers.

\section{INTRODUCTION}

$\mathbf{P}$ ULSED operation of lasers is quite useful for several material processing applications [1]. The quasi-CW operation of neodymium lasers make them desirable for various material processing applications such as hole piercing, deep key hole welding, and cutting [1]-[3]. It was found quite early that the lifetime of the lamp could be significantly increased if the gas in the lamp was preionized [4]. Flashlamp-pumped solid-state lasers, therefore, use the simmer mode of operation in which flashlamps are kept ionized by a low current discharge maintained between the high current pulses. Typical values of the dc simmer current lie between $25 \mathrm{~mA}$ to several amperes [5]. Preionization provides the additional advantage of improving the flashlamp efficiency [6], [7] and is therefore widely used for these solid-state lasers. Gains in efficiency as high as $100 \%$, as a result of preionization, are reported for short-pulsed flashlamps used in dye lasers [8]-[10]. For the majority of quasi-CW solidstate lasers, flashlamps are driven by a pulsed current having a duration in the range of 1-20 ms; the gain in efficiency is not of this level.

In this paper, investigations of the influence of dc simmer current on the output of a Nd:YAG laser operating in the quasi-CW

Manuscript received November 15, 1999; revised March 3, 2000

R. Arya, A. G. Bhujle, and D. D. Bhawalkar are with the Centre for Advanced Technology, Indore 452 013, India.

J. M. Thomas is with the Department of High Voltage Engineering, Indian Institute of Science, Bangalore 560 012, India.

Publisher Item Identifier S 0018-9197(00)05352-5. mode with an output pulsewidth in the range of 1-10 ms are reported. This laser is capable of giving high average power (hundreds of watts) and can operate at high repetition rates (typically $100-500 \mathrm{~Hz}$ ). In the experiment described here, the lasing medium was pumped by using a pulse power source with a provision of the fine adjustment in current pulse parameters, i.e., pulsewidth, pulsed-current magnitude, and pulse repetition rate over a wide range.

The experimental results presented show that the flashlamp impedance and correct arc diameter depend on the value of the dc simmer current and, therefore, the peak current is varied by the changes in the simmer current. The conversion efficiency also improves with the simmer current as the pump source efficiency improves with an increase in the correct arc diameter.

\section{THEORY}

The Goncz relation, describing the relation between the flashlamp voltage and the flashlamp current during a discharge pulse, states that the voltage is always proportional to the square root of the current in the high-current regime [4]:

$$
V_{o}=K_{o} \sqrt{I_{o}} .
$$

The flashlamp impedance parameter $K_{\circ}$ depends on the geometric dimensions of the flashlamp, such as the arc length $l$ and the bore diameter $d$ of the lamp, and on the lamp filling (e.g., the kind of gas and the pressure $p$ ). For xenon, the following relation holds where pressure $p$ is in torr [4]:

$$
K_{o}=1.27(p / 450)^{0.2} l / d .
$$

In (2a), the whole cross section of the flashlamp is assumed to be ionized. Because the instantaneous arc diameter is not identical to the geometric inner diameter of the lamp, (2a) has to be modified. The bore diameter is replaced by the correct arc diameter $d_{a}$ as proposed by Dishington et al. [11]

$$
K_{o}=1.27(p / 450)^{0.2} l / d_{a} .
$$

Therefore, for a fixed value of pressure $p$ and arc length $l$, the flashlamp impedance is no longer a constant but depends on $d_{a}$. The dependence of flashlamp impedance parameter on $d_{a}$ can, in turn, be used to define the correct arc diameter $d_{a}$ :

$$
d_{a}=1.27(p / 450)^{0.2} l / K_{o} .
$$

The dynamic behavior in the discharge circuit, which consists of a flashlamp, a capacitance, and an inductance, is described by 
a nonlinear differential equation that contains the Goncz relation. To classify the numerical solutions of the flashlamp current while neglecting any Ohm's resistance, Marciewicz and Emmett [12] introduced the parameter $\alpha$. By computer simulation, the most accurate value for $\alpha_{o}$ ( $\alpha$ for the critically damped case) was calculated to be 0.84 by Brown and Nee [13], whereas smaller values have been reported before [12], [14].

In the present experiment, the flashlamp was driven by rectangular pulsed currents in place of pulses generated by critically damped $R L C$ discharge circuits used for narrower pulses or by multiple-mesh pulse forming networks. A buck converter operating at high frequency and in the burst mode was used, the details of which are reported elsewhere [15], to generate the rectangular pulses with provisions for pulse parameter adjustment. It facilitates the fine adjustment in pulsewidth, current, and repetition rate over a wide range. The output voltage of the converter-based pulse power source depends on input voltage $V_{\text {in }}$ and the duty ratio $D$ of the switch as given by [16]

$$
V_{o}=D V_{\mathrm{in}}
$$

The current $I_{O}$ through the flashlamp can also be controlled by the duty ratio through the control function, as given by

$$
I_{o}=K_{v} D^{2}
$$

will not be linear (where $K_{v}=\left(V_{\text {in }} / K_{o}\right)^{2}$ ).

The parameter $K_{v}$, which depends on input voltage $V_{\text {in }}$ and flashlamp impedance parameter $K_{o}$, can be treated as constant for a constant input voltage and for the lamp operating in the high-current regime.

The reflection of the ripple current, through the flashlamp, in the laser output can be minimized by choosing a high switching frequency $f_{s}$ (30 kHz in the present experiment). In addition, the output voltage fluctuations $\Delta V_{o}$ given by

$$
\Delta V_{o} / V_{o}=0.5 \pi^{2}(1-D)\left(f_{c} / f_{s}\right)^{2}
$$

are very much reduced by using a low-pass filter with appropriate corner frequency $f_{c}$ [16]

This will result in a peak-to-peak current ripple $\Delta I_{o}$ given by

$$
\Delta I_{o} / I_{o}=\pi^{2}(1-D)\left(f_{c} / f_{s}\right)^{2}
$$

through the flashlamp having a $V-I$ characteristic in the region of interest as per (1).

By choosing appropriate values of switching and corner frequency, the peak-to-peak ripple current can be contained so as to result in a negligibly small contribution in laser output. Using a converter-based pulse power source, the laser could be pumped by rectangular pulsed currents, through the flashlamp with desirable pulse parameters, in the pulse duration range of 1-20 ms to study the effect of the simmer current on laser output operating in the quasi-CW mode.

\section{EXPERIMENTAL SETUP}

A simplified schematic diagram of the experimental arrangement used for the study is shown in Fig. 1. It consists of the following subsystems.

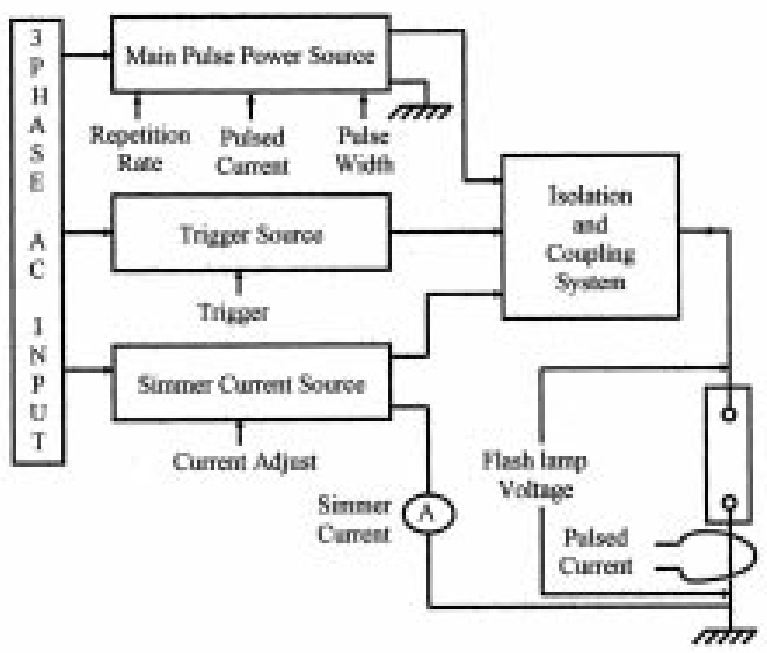

Fig. 1. Schematic diagram of the experimental arrangement for measurement of flash lamp pulsed-current and voltage.

\section{A. The Pulsed Power Source}

A pulsed power source, with adjustable output current-pulse parameters, specifically developed for this purpose was used. It can deliver an average output power of $2 \mathrm{~kW}$ and a peak output power of $50 \mathrm{~kW}$ to drive the flashlamp-pumped quasi-CW $\mathrm{Nd}$ :YAG laser oscillator to get an average power output up to $20-40 \mathrm{~W}$. It uses a series type of chopper to facilitate fine adjustment in pulse parameters (i.e., pulsewidth, current, and repetition rate) over a wide range. The output current is continuously adjustable from 50 to $200 \mathrm{~A}$, the pulsewidth from 1 to $20 \mathrm{~ms}$, and the repetition rate from 1 to 500 pulses per second.

\section{B. The Simmer Current Source}

For studying the effects of simmer current on flashlamp impedance and laser output, a simmer current source which can deliver an adjustable stable current from $30 \mathrm{~mA}$ to $6 \mathrm{~A}$ through the flashlamp has been developed along with a trigger system using a parallel trigger technique. Different values of ballast resistors are used to get different ranges of stable simmer current. To keep the power dissipation in ballast resistors within reasonable limits even for higher values of simmer current, different dc power sources, with suitable maximum voltage and power capabilities, are used with these ballast resistors. These power sources are kept active individually or in combination, depending upon the current requirements.

At the time of triggering, the simmer current source is operated at $100 \mathrm{~mA}$ of current and is then adjusted as per the requirements. This requires only a 45-kV 200-mA diode stack to be used for isolating the simmer current source from the trigger source high-voltage pulses, even for a simmer current requirement of 6 A. The high-voltage low-current source is kept active in parallel with the high current source to avoid extinction of the simmer, due to lower output voltage from the high current source, just after the main pulsed discharge. 


\section{The Laser System}

The experiments were carried out using an optical pumping chamber with separate axial holes for the laser rod and for the flashlamp as well as a water circulation arrangement for cooling them. The pump cavity from inside was a highly reflective elliptical cylinder with the laser rod and flashlamp pump at each focal line. The flashlamp had an impedance parameter of $16.2 \mathrm{~V} / \sqrt{A}$, an arc length of $76.2 \mathrm{~mm}$, and a bore diameter of $5 \mathrm{~mm}$. The laser rod was $8 \mathrm{~mm}$ in diameter and $85 \mathrm{~mm}$ long, with perpendicular flat ends without an antireflective coating. The optical resonator had a length of $40 \mathrm{~cm}$ and consisted of a high reflector with a 5-m radius of curvature and a flat output coupler with a transmission of $50 \%$.

\section{The Cooling System}

The efficiency of a quasi-CW Nd:YAG laser is typically 1\%-2\%. Therefore, almost $98 \%-99 \%$ of the input energy appears as heat which has to be extracted from the optical pump cavity by an appropriate cooling system. The laser rod and flashlamp are cooled separately and the temperature of the pumping cavity is maintained between $14{ }^{\circ} \mathrm{C}-20{ }^{\circ} \mathrm{C}$. The cooling system uses distilled and deionized water as the coolant.

\section{E. The Measurements and Instruments}

The flashlamp was driven by the pulsed power source in the presence of a simmer current discharge for carrying out the experimental study. The data for the flashlamp current, voltage, and laser output energy per pulse were recorded under operation at a repetition rate of one pulse per second to avoid the influence of repetition rate on flashlamp impedance and, thus, ensuring that the effects on flashlamp parameters are due to simmer current only. These data were averaged for 10 consecutive pulses to account for pulse-to-pulse variations. The signals were recorded using a digital storage oscilloscope, LeCroy model 9314A, with a bandwidth of $400 \mathrm{MHz}$ and a sampling rate of $100 \mathrm{MS} / \mathrm{s}$ from which the data were transferred to a PC for storage and further analysis. To ensure correct measurements of the pulsed current through the flashlamp, a pulse transformer designed and fabricated for this purpose was calibrated using a shunt that had a resistance of $5 \mathrm{~m} \Omega$ with an accuracy of $1 \%$. An oscilloscope probe with an attenuation ratio of 100:1 and a bandwidth of $200 \mathrm{MHz}$ was used to measure the voltage across the flashlamp. The laser energy was measured by using a Gentec model ED200 energy meter along with the above-mentioned scope. The calibration of the energy meter was confirmed experimentally with another recently calibrated energy meter (Gentec model ED200). The energy meter output was also averaged for the same 10 consecutive pulses, for which current and voltage pulses were averaged, and stored.

\section{EXPERIMENTAL STUDY}

The power conditioning system for the flashlamp-pumped solid-state laser was connected to feed the flashlamp in the pumping chamber. To begin with, the cooling system was activated and then the input contactor was energized to feed the power to the power-conditioning system for the laser. The
TABLE I

CONVERSION EFFICIENCY AS A FUNCTION OF SiMMER CURRENT FOR Flashlamp CURRENT PULSEWIDTH VAlues OF0.85, 1.35, 1.85 AND $2.85 \mathrm{~ms}$

\begin{tabular}{|c|c|c|c|c|}
\hline \multirow{3}{*}{$\begin{array}{l}\text { Simmer } \\
\text { current } \\
\text { (mA) }\end{array}$} & \multicolumn{4}{|c|}{ Conyersion efficiency $(\%)$} \\
\hline & \multicolumn{4}{|c|}{ (a) Current pulse width } \\
\hline & $0.85 \mathrm{~ms}$ & $1.35 \mathrm{~ms}$ & $1.85 \mathrm{~ms}$ & $2.85 \mathrm{~ms}$ \\
\hline 30 & 1.07 & 1.42 & 1.61 & 1.70 \\
\hline 40 & 1.23 & 1.55 & 1.68 & 1.70 \\
\hline 50 & 1.37 & 1.61 & 1.73 & 1.73 \\
\hline 60 & 1.48 & 1.70 & 1.75 & 1.78 \\
\hline 70 & 1.79 & 1.66 & 1.73 & 1.77 \\
\hline 80 & 1.79 & 1.69 & 1.80 & 1.78 \\
\hline 90 & 1.82 & 1.75 & 1.79 & 1.79 \\
\hline 100 & 1.79 & 1.70 & 1.77 & 1.79 \\
\hline 200 & 1.93 & 1.88 & 1.84 & 1.83 \\
\hline 300 & 1.87 & 1.90 & 1.86 & 1.82 \\
\hline 400 & 1.92 & 1.97 & 1.87 & 1.83 \\
\hline 500 & 1.97 & 1.97 & 1.88 & 1.84 \\
\hline 1000 & 2.01 & 1.92 & 1.87 & 1.82 \\
\hline 1500 & 2.07 & 1.94 & 1.87 & 1.81 \\
\hline 2000 & 2.08 & 1.92 & 1.85 & 1.84 \\
\hline 2500 & 2.13 & 1.93 & 1.83 & 1.84 \\
\hline 3000 & 2.13 & 1.94 & 1.85 & 1.84 \\
\hline 3500 & 2.10 & 1.98 & 1.82 & 1.84 \\
\hline 4000 & 2.10 & 1.99 & 1.86 & 1.83 \\
\hline 4500 & 2.14 & 1.97 & 1.85 & 1.83 \\
\hline 5000 & 2.13 & 2.00 & 1.85 & 1.81 \\
\hline
\end{tabular}

simmer current source was then applied and the flashlamp was triggered under applied bias voltage from the current source. The triggering causes the simmer current to flow through the flashlamp, which is adjusted to get the required value of $100 \mathrm{~mA}$. The main pulse power source isolation switch, incorporated in the isolation and coupling system, is switched on to feed the pulsed power after sensing the water flow, the temperature of coolant water flowing through the pumping chamber, and the appropriate simmer current magnitude. For these experiments, the pulsewidth of the flashlamp current pulse is adjusted for $100 \mathrm{~mA}$ of the simmer current as the pulsewidth varies slightly with a change in simmer current value.

To determine the dependence of the laser output on the simmer current, the averaged waveform of the voltage across the flashlamp, the current through it as a function of time, and the laser output energy per pulse were recorded simultaneously at selected values of the pulsewidth for simmer currents varying from $30 \mathrm{~mA}$ to $5 \mathrm{~A}$ in a large number of steps. The experiment was carried out at a minimum adjustable pulsewidth of $0.85 \mathrm{~ms}$ and at other pulsewidths of $1.35,1.85$, and $2.85 \mathrm{~ms}$. The electrical pump energy and conversion efficiency were calculated from these experimentally measured parameters. The electrical pump energy is the electrical energy per pulse delivered to the flashlamp. The conversion efficiency is the ratio of the laser output energy per pulse and the corresponding electrical pump energy. The values of conversion efficiency under various settings of simmer current at these current pulsewidths are summarized in Table I. 
The conversion efficiency, for a pulsewidth of $0.85 \mathrm{~ms}$, improves from about $1 \%$ at $30 \mathrm{~mA}$ to about $2 \%$ at $1 \mathrm{~A}$ of simmer current; beyond this value, the improvement in efficiency is negligibly small. For current pulsewidth values of 1.35, 1.85, and $2.85 \mathrm{~ms}$, the improvement in efficiency is observed up to 400,300 , and $200 \mathrm{~mA}$, respectively, and beyond these values of simmer current no appreciable improvement is observed. It is noted from these results that the efficiency improves with increasing simmer current value considerably up to $500 \mathrm{~mA}$ but does not improve further, which was experimentally verified up to $5 \mathrm{~A}$.

For an investigation of the gain in pump efficiency, which is not totally understood, the flashlamp impedance is examined as a function of the simmer current, from which the correct arc diameter [11], [17] is calculated. The observation of the correct arc diameter allows one to describe the effect of the simmer current on the flashlamp discharge.

From the measured parameters at pulsewidth values of 0.85 , $1.35,1.85$ and $2.85 \mathrm{~ms}$ and at large number of simmer current values in the range from $30 \mathrm{~mA}$ to $5 \mathrm{~A}$, the flashlamp impedance parameter and flashlamp correct arc diameter were calculated. The flashlamp impedance parameter $K_{0}$ was determined according to the Goncz relation, as given in (1), from the corresponding measured values of voltage and current during the whole discharge. The value of correct arc diameter was calculated from measured flashlamp impedance according to (2c).

The flashlamp impedance parameter $K_{0}$ was found to decrease with an increase in the simmer current. The impedance offered by the flashlamp was higher for narrower pulses at the same value of simmer current in the lower range and approached a final value at higher levels of simmer current. The total percentage change decreased with increasing pulsewidth, and flashlamp impedance approached the final value at lower values of simmer current for wider pulses.

It is also observed that the correct arc diameter increased with rising simmer current and approached the geometric bore diameter of the lamp tube at higher values of simmer current. The total percentage change in correct arc diameter decreased with increasing pulsewidth and it approached the geometric bore diameter, for wider pulses, at lower values of simmer current. It approached the geometric bore diameter of the tube between $600 \mathrm{~mA}$ and $1 \mathrm{~A}$ for $0.85 \mathrm{~ms}$, at $500 \mathrm{~mA}$ for $1 \mathrm{~ms}$, between 400 and $500 \mathrm{~mA}$ for $1.35 \mathrm{~ms}$, and between 100 to $200 \mathrm{~mA}$ for $2.85 \mathrm{~ms}$.

For the study of the relative effect of simmer current on laser output with different values of pulsewidth, flashlamp pulsed current, voltage, and output laser energy per pulse were recorded at pulsewidths from 1 to $10 \mathrm{~ms}$ at an interval of $1 \mathrm{~ms}$ with the same setting and alignment of the laser system and other instruments. The temporal evolution of the pulsed current and voltage across the flashlamp observed as a function of the simmer current but for identical input is shown in Fig. 2. As the conversion efficiency improved up to a simmer current of $500 \mathrm{~mA}$ for the current pulsewidths varying from 0.85 to $2.85 \mathrm{~ms}$, further measurements for current pulsewidths $1-10 \mathrm{~ms}$ were carried out only at five selected simmer current values of 30,50, 100, 200, and $500 \mathrm{~mA}$. Flashlamp pulsed-current density was kept approximately at $1000 \mathrm{~A} / \mathrm{cm}^{2}$ for this set of experiments.
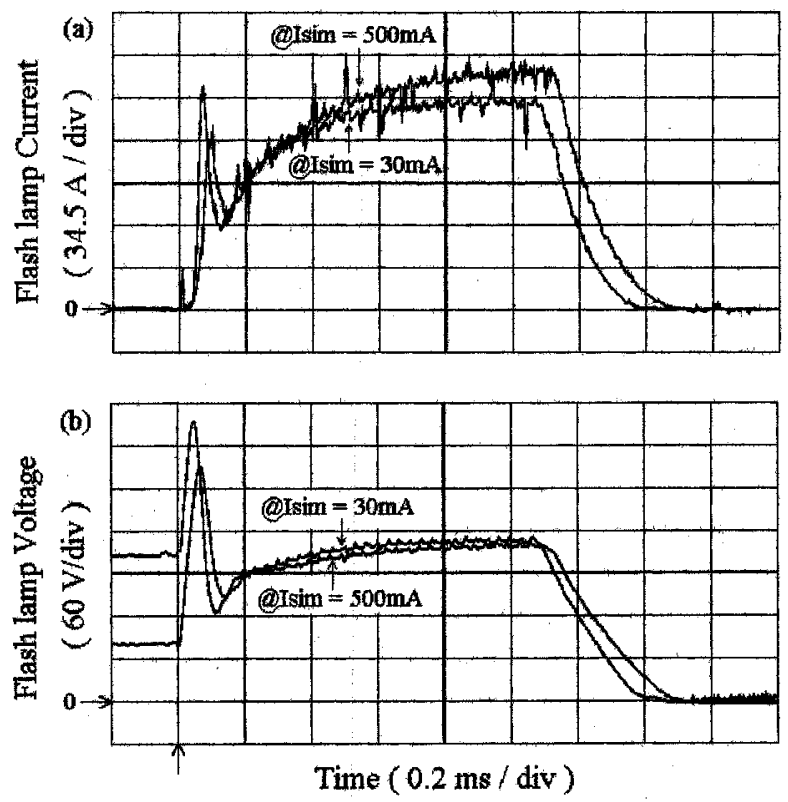

Fig. 2. Flashlamp (a) pulsed-current and (b) pulsed-voltage waveforms for two different values of simmer current. The signals were averages over 10 pulses.

The electrical pump energy per pulse delivered to the flashlamp was increased from 40 to $400 \mathrm{~J}$ in steps of $40 \mathrm{~J}$ with a peak power dissipation of $40 \mathrm{~kW}$ and corresponding laser output energy per pulse varied from 0.5 to $7.5 \mathrm{~J}$. The pulsed current, voltage, and laser energy per pulse measured at these values of pulsewidth and simmer current are tabulated in Tables II-IV, respectively. The electrical pump energy and conversion efficiency were calculated from the measured parameters for each setting of pulsewidth and simmer current values. The conversion efficiency values at these different settings are summarized in Table V and are also plotted in Fig. 3. Corresponding flashlamp impedance and correct arc diameter were calculated, from the recorded parameters at different pulsewidth values from 1 to $10 \mathrm{~ms}$, and are plotted as functions of simmer current in Figs. 4 and 5 , respectively.

\section{RESULTS AND DISCUSSION}

The laser output energy was observed as a function of the simmer current for different values of pulsewidth from 1 to $10 \mathrm{~ms}$. The conversion efficiency increased with increasing simmer current. As the only change, which caused this improvement in conversion efficiency of the laser system, is a change in the simmer current, it can be concluded that the pump source efficiency improves with this change in simmer current. The experimental results obtained for conversion efficiency at different pulsewidths from 1 to $10 \mathrm{~ms}$ are plotted as a function of simmer current in Fig. 3. Clearly, the strongest change in the efficiency occurs when the simmer current is increased from 30 to $500 \mathrm{~mA}$. For simmer currents greater than $500 \mathrm{~mA}$, the laser efficiency reaches nearly a constant value. The $100 \%$ improvement in efficiency [i.e., from $1 \%$ to $2 \%$ due to simmer current at a pulsewidth of $0.85 \mathrm{~ms}$ (see Table I)] is significantly larger than the relative uncertainties. The effect, due to an increase in simmer current, is reduced as the pulsewidth became wider. 
TABLE II

Flashlamp Pulsed CuRRENT AS a FunCtion of SimMer CURRENT For DiFFERENT VALUES OF PULSEWIDTH FROM 1 TO $10 \mathrm{~ms}$

\begin{tabular}{l|l|l|l|l|l}
\hline \multirow{2}{*}{$\begin{array}{l}\text { Pulse } \\
\text { width } \\
(\mathbf{m s})\end{array}$} & \multicolumn{5}{|c}{ Flash lamp pulsed-current (A) } \\
\cline { 2 - 6 } & $\begin{array}{l}\text { @ Isim } \\
\mathbf{3 0} \mathbf{~ m A}\end{array}$ & $\begin{array}{l}\text { @ Isim } \\
\mathbf{5 0 ~} \mathbf{~ m A}\end{array}$ & $\begin{array}{l}\text { @ Isim }= \\
\mathbf{1 0 0} \mathbf{~ m A}\end{array}$ & $\begin{array}{l}\text { @ Isim }= \\
\mathbf{2 0 0} \mathbf{~ m A}\end{array}$ & $\begin{array}{l}\text { @ Isim }= \\
\mathbf{5 0 0 ~} \mathbf{~ m A}\end{array}$ \\
\hline 1.0 & 164.4 & 171.6 & 182.5 & 184.8 & 185.1 \\
\hline 1.5 & 168.0 & 177.6 & 184.1 & 184.9 & 184.6 \\
\hline 2.0 & 168.3 & 177.6 & 181.0 & 183.5 & 184.1 \\
\hline 3.0 & 171.1 & 179.4 & 183.2 & 186.1 & 189.4 \\
\hline 4.0 & 179.1 & 184.3 & 187.8 & 190.1 & 200.0 \\
\hline 5.0 & 179.5 & 180.1 & 182.4 & 186.5 & 191.1 \\
\hline 6.0 & 173.4 & 179.2 & 180.1 & 184.4 & 186.7 \\
\hline 7.0 & 175.2 & 176.0 & 178.9 & 182.3 & 186.6 \\
\hline 8.0 & 175.3 & 175.2 & 183.0 & 185.2 & 190.1 \\
\hline 9.0 & 174.6 & 180.5 & 181.7 & 185.6 & 188.6 \\
\hline 10 & 173.9 & 177.6 & 184.3 & 186.5 & 189.3 \\
\hline
\end{tabular}

TABLE III

Flashlamp Pulsed Voltage as a FunCtion of SimMer CURRENT For DifFERENT VALUES OF CURRENT PULSEWIDTH FROM 1 TO $10 \mathrm{~ms}$

\begin{tabular}{|c|c|c|c|c|c|}
\hline \multirow{2}{*}{$\begin{array}{l}\text { Pulse } \\
\text { width } \\
\text { (ms) }\end{array}$} & \multicolumn{5}{|c|}{ Flash lamp pulsed-voltage (V) } \\
\hline & $\begin{array}{l}\text { (a) Isim= } \\
30 \mathrm{~mA}\end{array}$ & $\begin{array}{l}\text { @ Isim = } \\
\mathbf{5 0 ~ m A}\end{array}$ & $\begin{array}{l}\text { (a) } \text { Isim }= \\
100 \mathrm{~mA}\end{array}$ & $\begin{array}{l}\text { (a) Isim = } \\
200 \mathrm{~mA}\end{array}$ & $\begin{array}{l}\text { @ } \operatorname{Isim}= \\
500 \mathrm{~mA}\end{array}$ \\
\hline 1 & 230.2 & 227.7 & 224.8 & 222.9 & 221.0 \\
\hline 1.5 & 232.2 & 227.8 & 224.5 & 222.5 & 222.2 \\
\hline 2 & 230.7 & 225.2 & 223.2 & 221.2 & 220.7 \\
\hline 3 & 226.5 & 222.3 & 222.8 & 221.7 & 220.3 \\
\hline 4 & 225.7 & 223.7 & 224.2 & 223.8 & 222.5 \\
\hline 5 & 222.7 & 218.5 & 217.8 & 216.6 & 215.3 \\
\hline 6 & 217.0 & 213.8 & 213.3 & 211.8 & 210.2 \\
\hline 7 & 215.0 & 212.2 & 209.3 & 209.3 & 209.3 \\
\hline 8 & 212.5 & 206.3 & 210.3 & 209.9 & 209.5 \\
\hline$\overline{9}$ & 208.7 & 208.2 & 207.2 & 207.2 & 206.7 \\
\hline 10 & 206.2 & 207.3 & 207.8 & 207.4 & 207.0 \\
\hline
\end{tabular}

The percentage increase in efficiency decreased from about $27 \%$ to only about $1 \%$, when the pulsewidth was increased from 1 to $7 \mathrm{~ms}$ for simmer current varying from 30 to $100 \mathrm{~mA}$. The percentage increase in conversion efficiency for pulsewidth values of 2,3 , and $5 \mathrm{~ms}$, for the identical change in simmer current, is observed to be $15 \%, 7 \%$, and $5 \%$ respectively.

The experimental results obtained for flashlamp impedance are plotted as a function of simmer current for different values of current pulsewidth in Fig. 4. The impedance factor $K_{0}$ decreased with increasing simmer current. Although at lower simmer currents the flashlamp impedance decreased faster with increasing simmer current, it reaches a nearly constant value at a simmer current of about $500 \mathrm{~mA}$. The flashlamp current and voltage waveforms for different values of simmer current (see Fig. 2) show an increase in peak current and a decrease in voltage across the flashlamp with increasing simmer current. A change in flashlamp impedance of about $13 \%$ and about $11 \%$ at pulsewidths of 0.85 and $1 \mathrm{~ms}$, respectively, are significantly higher than the uncertainties in the experimental measurements, which are not more than $4 \%$. The change in flashlamp impedance decreased with increase in pulsewidth as
TABLE IV

LASER OUtPut ENERgy Per PulSE AS A FunCtion OF SimMER CURRENT For DifFERENT VALUES of CURRENT PULSEWIDTh From 1 TO $10 \mathrm{~ms}$

\begin{tabular}{|c|c|c|c|c|c|}
\hline \multirow{2}{*}{$\begin{array}{l}\text { Pulse } \\
\text { width } \\
\text { (ms) }\end{array}$} & \multicolumn{5}{|c|}{ Laser output energy per pulse $(J)$} \\
\hline & $\begin{array}{l}\text { @ } \mathbf{I s i m}= \\
\mathbf{3 0} \mathbf{~ m A}\end{array}$ & $\begin{array}{l}@ \text { Isim }= \\
50 \text { mA }\end{array}$ & $\begin{array}{l}\text { (a) } \mathbf{I s i m}= \\
100 \mathrm{~mA}\end{array}$ & $\begin{array}{l}@ \text { @ Isim }= \\
200 \mathrm{~mA}\end{array}$ & $\begin{array}{l}\text { @ Isim = } \\
500 \mathrm{~mA}\end{array}$ \\
\hline 1 & 0.498 & 0.580 & 0.690 & 0.755 & 0.765 \\
\hline 1.5 & 0.964 & 1.084 & 1.203 & 1.222 & 1.277 \\
\hline 2 & 1.373 & 1.551 & 1.648 & 1.701 & 1.738 \\
\hline 3 & 2.138 & 2.309 & 2.405 & 2.445 & 2.494 \\
\hline 4 & 2.956 & 3.081 & 3.333 & 3.387 & 3.556 \\
\hline 5 & 3.816 & 3.986 & 3.994 & 4.141 & 4.223 \\
\hline 6 & 4.328 & 4.410 & 4.669 & 4.663 & 4.632 \\
\hline 7 & 5.144 & 5.173 & 5.173 & 5.312 & 5.530 \\
\hline 8 & 5.738 & 5.715 & 6.094 & 6.251 & 6.555 \\
\hline 9 & 6.532 & 6.681 & 6.726 & 6.898 & 7.023 \\
\hline 10 & 7.014 & 7.119 & 7.311 & 7.504 & 7.594 \\
\hline
\end{tabular}

TABLE $\mathrm{V}$

CONVERSION EFFICIENCY AS A FUNCTION OF SIMMER CURRENT FOR DifFerent VALUES of CURRENT PULSEWIDTH From 1 TO $10 \mathrm{~ms}$

\begin{tabular}{l|l|l|l|l|l}
\hline \multirow{2}{*}{$\begin{array}{l}\text { Pulse } \\
\text { width } \\
\text { (ms) }\end{array}$} & \multicolumn{5}{|c}{ Conversion efficiency (\%) } \\
\cline { 2 - 6 } & $\begin{array}{l}\text { @ Isim }= \\
\mathbf{3 0} \mathbf{~ m A}\end{array}$ & $\begin{array}{l}\text { @ Isim }= \\
\mathbf{5 0} \mathbf{~ m A}\end{array}$ & $\begin{array}{l}\text { @ Isim }= \\
\mathbf{1 0 0} \mathbf{~ m A}\end{array}$ & $\begin{array}{l}\text { @ Isim }= \\
\mathbf{2 0 0} \mathbf{~ m A}\end{array}$ & $\begin{array}{l}\text { @ Isim }= \\
\mathbf{5 0 0 ~} \mathbf{~ A}\end{array}$ \\
\hline 1 & 1.343 & 1.515 & 1.716 & 1.834 & 1.909 \\
\hline 1.5 & 1.631 & 1.769 & 1.921 & 1.980 & 2.052 \\
\hline 2 & 1.768 & 1.939 & 2.039 & 2.095 & 2.138 \\
\hline 3 & 1.838 & 1.930 & 1.964 & 1.975 & 1.992 \\
\hline 4 & 1.828 & 1.869 & 1.979 & 1.990 & 1.998 \\
\hline 5 & 1.930 & 2.048 & 2.033 & 2.050 & 2.075 \\
\hline 6 & 1.907 & 1.909 & 2.015 & 1.990 & 1.958 \\
\hline 7 & 1.940 & 1.968 & 1.963 & 1.989 & 2.012 \\
\hline 8 & 1.930 & 1.982 & 1.984 & 2.010 & 2.062 \\
\hline 10 & 1.985 & 1.969 & 1.978 & 1.991 & 1.995 \\
\hline & 1.956 & 1.934 & 1.909 & 1.940 & 1.938 \\
\hline
\end{tabular}

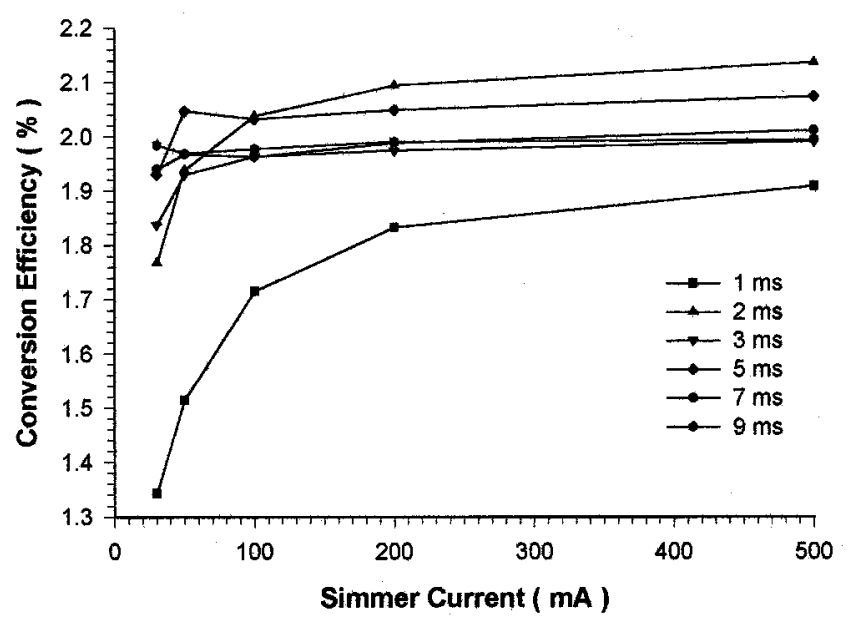

Fig. 3. Conversion efficiency plotted as a function of simmer current for different values of current pulsewidth.

can be seen from Fig. 4. The percentage change in flashlamp impedance decreased from $11 \%$ at $1 \mathrm{~ms}$ to only $3 \%$ at $5 \mathrm{~ms}$. 


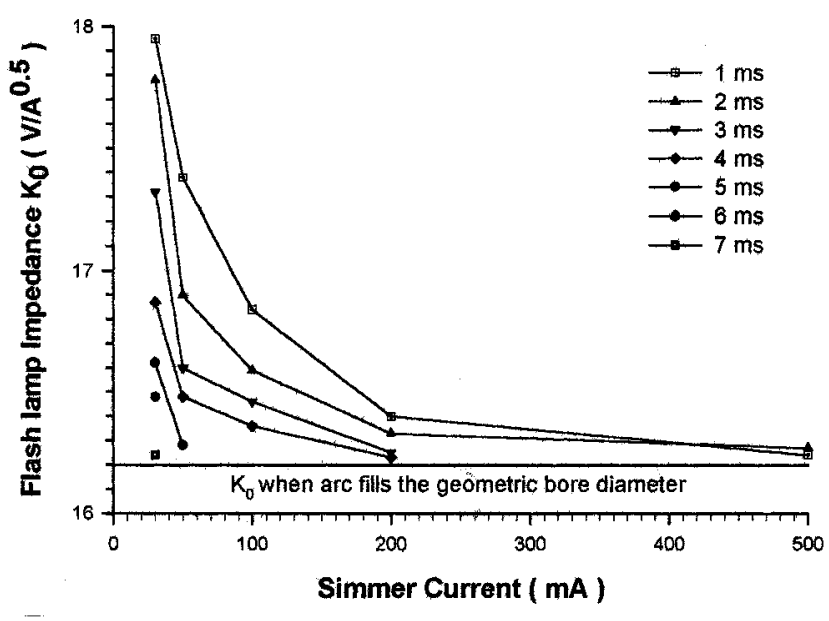

Fig. 4. Dependence of the flashlamp impedance on the simmer current for different values of current pulsewidth.

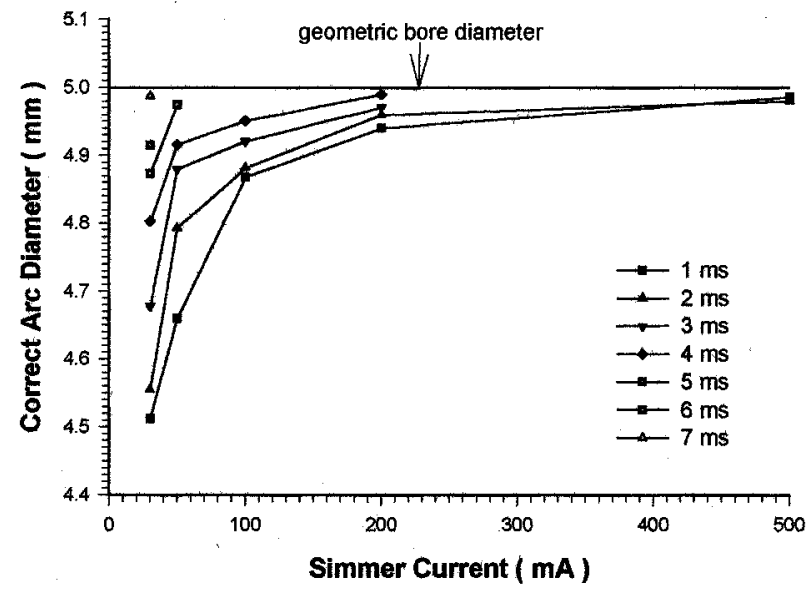

Fig. 5. Dependence of the correct arc diameter on the simmer current for different values of current pulsewidth.

The change for other pulsewidth values of 2,3 , and $4 \mathrm{~ms}$ is observed to be $10 \%, 7 \%$, and $4 \%$, respectively.

The results for correct arc diameter at different pulsewidth values from 1 to $10 \mathrm{~ms}$ are plotted as a function of the simmer current in Fig. 5. The correct arc diameter $d_{a}$ increased with simmer current. Even though the total increase is small $(10 \%$ relative to the bore diameter), it is higher than the relative uncertainties and, hence, it can be concluded that $d_{a}$ is being influenced by the simmer current. When the simmer current exceeds $500 \mathrm{~mA}$, the correct arc diameter approached a constant value even for a pulsewidth of $1 \mathrm{~ms}$, which was found to be the same as the geometric bore diameter of the flashlamp. As a consequence, the peak current of the flashlamp was found to increase with the simmer current. The percentage change in arc diameter decreased with an increase in current pulsewidth. The change relative to the geometric bore diameter decreased from about $10 \%$ at $1 \mathrm{~ms}$ to about $3 \%$ only at $5 \mathrm{~ms}$. At pulsewidths of 2, 3, and $4 \mathrm{~ms}$, the percentage change is observed to be $9 \%, 6 \%$, and $4 \%$, respectively.

It can be observed that, for pulsewidths greater than $4 \mathrm{~ms}$, the correct arc diameter fills the geometric bore diameter of $100 \mathrm{~mA}$ of the simmer current. It can also be observed that the efficiency of the laser system improves up to $100 \mathrm{~mA}$ of simmer current at a pulsewidth value of more than $4 \mathrm{~ms}$, and no further improvement in efficiency is observed at a pulsewidth of $5 \mathrm{~ms}$ for higher simmer current. The correct arc diameter approaches the bore diameter between $600 \mathrm{~mA}$ to $1 \mathrm{~A}$ at a pulsewidth of $0.85 \mathrm{~ms}$, and it can clearly be observed that the efficiency also attains nearly a constant value for simmer currents higher than $1 \mathrm{~A}$. A similar trend can be observed, for all other values of the pulsewidth from 1 to $10 \mathrm{~ms}$, that the efficiency also approaches nearly a constant value when the arc completely fills the geometric bore diameter of the flashlamp. The fact that the flashlamp efficiency is improved as a consequence of the increase of the correct arc diameter is in agreement with experimental results obtained for the lamp intensity [18].

The increase in correct arc diameter with an increase in simmer current causes the flashlamp current density to decrease. The best spectral overlap of the neodymium absorption bands with the spectrum of a xenon-filled flashlamp occurs at a color temperature of 4500-4700 K, which occurs at a low current density compared to those at which lamps are operated. At higher current densities, the lamp spectrum shifts to shorter wavelengths and the line emission becomes less prominent [19]. This also explains why the conversion efficiency is improved with an increase in simmer current in the region in which the correct arc diameter increases with the simmer current. The work done by earlier researchers [19], [20] also tends to indicate that the xenon flashlamp pumping efficiency for neodymium lasers monotonically increases with decreasing current density.

Also, the flashlamp light, which is not absorbed in the rod on the first pass, will be rereflected to the flashlamp as an elliptical cylinder imaging pump cavity was used. As the lamp current density is reduced, the optical opacity of the flashlamp arc is also reduced [21]. The cavity transfer efficiency decreases rapidly up to a current density of $1000 \mathrm{~A} / \mathrm{cm}^{2}$ with an increase in xenon flashlamp current density due to an increase in lamp arc opacity [20]. This effect can enhance the flashlamp pumping efficiency, especially for long pulses where the current density is low, for an imaging pump cavity.

The presence of these two mechanisms may be a part of the explanation of variation in maximum efficiency, shown in Fig. 3, with an increase in pulsewidth. Higher experimental precision may also be helpful in better understanding the effect of simmer current in the region of maximum efficiency.

With a proper choice of the simmer current value, the discharge becomes more homogeneous, which is characterized by the fact that the correct arc diameter fills the bore of the flashlamp and the correct peak current density decreases although the measured current increases. In this sense, a smaller correct peak current density may be seen as an indicator of a longer lifetime for flashlamps.

\section{CONCLUSIONS}

The influence of the simmer current on the laser output, flashlamp impedance, and correct arc diameter were studied for varying widths of current pulse through the flashlamp. 
The efficiency of the system was found to increase with simmer current up to a certain value and then remained nearly constant for further increases in simmer current. An optimized value of the simmer current can be determined for the system to get a better efficiency.

In addition, the flashlamp impedance was also studied along with correct arc diameter. It was found that the flashlamp impedance decreases and the correct arc diameter increases with increasing simmer current, which in turn provides a higher pump efficiency and also longer life of the flashlamps. The improvement in pump efficiency could be correlated with the increase in correct arc diameter. Therefore, an optimized value of the simmer current can be determined for the system to get not only better efficiency but also an improved flashlamp life.

The effect of simmer current on the output of the laser, flashlamp impedance and correct arc diameter was observed to reduce with increase in pulsewidth value and was quite negligible, for the present system, for pulsewidths wider than $5 \mathrm{~ms}$ and simmer current values higher than $500 \mathrm{~mA}$.

With appropriate choice of the simmer current value, the correct arc diameter fills the whole cross section of the flashlamp. As a consequence, the pump source efficiency and the laser output of a Nd:YAG laser are increased. At the same time, the lifetime of the flashlamp may be prolonged.

\section{ACKNOWLEDGMENT}

The authors would like to thank M. Kumar for providing technical assistance during the experiment. The authors are also grateful to the referee for the suggestions made regarding the influence of simmer current on the efficiency.

\section{REFERENCES}

[1] D. Belforte and M. Levitt, Industrial Laser Hand Book. New York, NY: Springer-Verlag, 1992, pp. 65-66.

[2] G. Chryssolouris, Laser Machining: Theory and Practice. New York, NY: Springer-Verlag, 1990, pp. 36-39.

[3] W. Burgese, "Laser diodes require the right power source," Laser Focus World, pp. 141-144, Mar. 1999.

[4] W. Koechner, Solid State Laser Engineering, 3rd ed. New York, NY: Springer-Verlag, 1992, ch. 6, pp. 285-336.

[5] B. Smith, "Overview of flash lamps and arc lamps," Proc. SPIE, vol. 609 , pp. $1-4,1986$

[6] A. C. Erlandson, "Pulse length scaling," in 1985 Laser Program Annual Report, M. L. Rufer and P. W. Murphy, Eds. Livermore, CA: Lawrence Livermore National Laboratory, 1986, ch. 7, p. 8.

[7] R. L. Stephens and W. F. Hug, "Simmering lamp lives longer," Laser Focus World, vol. 8, no. 7, pp. 38-40, 1972.

[8] A. Hirth, R. Meyer, and K. Schetter, "On the proper choice of the preionization mode of linear flash lamps," Opt. Commun., vol. 35, pp. 255-258, 1980.
[9] H. Furumoto, "State of the art high energy and high average power flash lamp excited dye-lasers," Proc. SPIE, vol. 609, pp. 111-128, 1986.

[10] T. K. Yee, B. Fan, and T. K. Gustfason, "Simmer enhanced flash lamp pumped dye laser," Appl. Opt., vol. 18, pp. 1131-1132, 1979.

[11] R. H. Dishington, W. R. Hook, and R. P. Hilberg, "Flash lamp discharge and laser efficiency," Appl. Opt., vol. 13, no. 10, pp. 2300-2312, 1974.

[12] J. P. Markiewicz and J. L. Emmett, "Design of flashlamp driving circuits," IEEE J. Quantum Electron., vol. QE-2, pp. 707-711, Nov. 1966.

[13] D. C. Brown and T. S. N. Nee, "Design of single flash lamp driving circuits with resistive losses," IEEE Trans. Electron Devices, vol. ED-24, pp. 1285-1287, 1977.

[14] J. F. Horzrichter and J. L. Emmett, "Design and analysis of high brightness axial flash lamp," Appl. Opt., vol. 8, pp. 1459-1465, 1969.

[15] R. Arya, J. M. Thomas, A. G. Bhujle, and D. D. Bhawalkar, "An arbitrary waveform pulsed power source for flash lamp pumped solid state lasers," Rev. Scientific Intruments, to be published.

[16] N. Mohan, T. M. Undeland, and W. P. Robbins, Power Electronics: Converters, Applications and Design, 2nd ed. New York, NY: Wiley, 1995, ch. 7, pp. 164-172.

[17] M. J. Kushner, "Arc expansion in xenon flash lamps," J. Appl. Phys., vol. 57, pp. 2486-2500, 1985.

[18] C. T. Fang and J. F. Lee, "Transient arc self-inductance and simmer current effects in linear flash lamps for laser pumping," Appl. Opt., vol. 25, pp. 92-96, 1986.

[19] W. E. Martin, J. B. Trenholme, G. J. Linford, S. M. Yarema, and C. A. Hurley, "Solid-state disc amplifiers for fusion system," IEEE $J$. Quantum Electron., vol. QE-17, pp. 1744-1755, July 1981.

[20] G. J. Linford, R. A. Saroyan, J. B. Trenholme, and M. J. Weber, "Measurements and modeling of gain coefficients of neodymium laser glasses," IEEE J. Quantum Electron., vol. QE-15, pp. 510-523, June 1979.

[21] J. L. Emmett, A. L. Schawlow, and D. E. Weingberg, "Direct measurement of xenon flashtube opacity," J. Appl. Phys., vol. 35, pp. 2601-2604, 1964.

R. Arya, photograph and biography not available at the time of publication.

Joy M. Thomas, photograph and biography not available at the time of publication.

A. G. Bhujle, photograph and biography not available at the time of publication.

D. D. Bhawalkar, photograph and biography not available at the time of publication. 